\title{
Corpo e Presença: experiências dentro e fora da sala de aula ${ }^{1}$
}

\author{
Cuerpo y Presencia: experiencias dentro y fuera del aula \\ Body and Presence: experiences inside and outside the classroom
}

Me. Rosane Tesch de Oliveira ${ }^{2}$

\begin{abstract}
Resumo
Em novembro de 2016, a professora Lúcia promoveu, em uma turma de Educação Infantil, uma exposição e uma apresentação de dança intituladas Ubuntu! e as atividades foram observadas e filmadas para análise, considerando as pesquisas com os cotidianos. Durante a análise, as intersecções entre o aqui e agora, o tempo real e o tempo virtual se apresentaram para além de qualquer configuração pré-concebida ou planejamento que pudesse prever uma experienciação. São os resultados dessa experiência estética, que toca o sujeito na pausa, na interrupção, no perigo e no estranhamento que movem esse texto em que são produzidos apontamentos sobre experiências que envolvem corpo e presença dentro e fora da sala de aula.
\end{abstract}

Palavras-Chave: Audiovisualidades; Corpo; Cotidianos; Educação; Experiência.

\section{Resumen}

En noviembre de 2016, la profesora Lúcia promovió una exposición y una presentación de danza titulada Ubuntu! en una clase de Educación Infantil y las actividades fueron observadas y filmadas para análisis, considerando las investigaciones con los cotidianos. Las intersecciones entre el aquí y ahora, el tiempo real y el tiempo virtual se presentaron más allá de cualquier configuración preconcebida o planificación que pudiera predecir una experiencia. Los resultados de esta experiencia estética, que toca al sujeto en la pausa, en la interrupción, en el peligro y en el extrañamiento mueven este texto en que se producen apuntes sobre experiencias con cuerpo y presencia dentro y fuera del aula.

Palabras claves: Audiovisualidad; Cuerpo; Cotidiano; Educación; Experiencia.

\begin{abstract}
In November 2016, teacher Lúcia promoted, in a class of Childhood Education, an exhibition and a dance presentation entitled Ubuntu! and the activities were observed and filmed for analysis, considering the researches with daily life. During the analysis, the intersections between the here and now, the real time and the virtual time presented themselves beyond any preconceived configuration or planning that could foresee an experience. It is the results of this aesthetic experience that touches the subject in the pause, interruption, danger and strangeness that move this text in which notes are produced about experiences involving body and presence inside and outside the classroom.
\end{abstract}

\footnotetext{
${ }^{1}$ Artigo apresentado no Simpósio Temático ST 07 - Experiências estéticas com a arte enquanto cultura, durante o II Seminário Latino-Americano de Estudos em Cultura - SEMLACult em Foz do Iguaçu/PR, Brasil, 2018.

${ }^{2}$ Doutoranda em Educação pelo Programa de Pós-graduação em Educação da Universidade Federal do Estado do Rio de Janeiro - PPGEDU/UNIRIO; Mestre em Educação pelo Programa de Pós-Graduação em Educação da Universidade do Estado do Rio de Janeiro - PROPED/UERJ; Membro do Grupo de Pesquisa Comunicação, Audiovisual, Cultura e Educação - CACE/UNIRIO. Rio de Janeiro, RJ, Brasil; rosanetesch@ gmail.com.
} 
Keywords: Audiovisuality; Body; Daily life; Education; Experience.

\section{Introdução: pesquisando com os cotidianos}

A cultura se julga pelas operações e não pela possessão dos produtos. $\mathrm{Na}$ arte, entender um quadro é reconhecer os gestos que lhe deram origem, a "pincelada", o "pincel", a "paleta" do "pintor".

Certeau; Giard; Mayol

O presente artigo tem como principal objetivo produzir apontamentos sobre experiências que envolvem corpo e presença dentro-fora da sala de aula de uma turma de Educação Infantil em uma unidade escolar pública da Zona Sul da cidade do Rio de Janeiro, Brasil, considerando as pesquisas com os cotidianos (ALVES, 2003) como referencial teórico e epistemológico. O cotidiano, longe da simplicidade que as expressões banalidade e rotina sugerem, é complexo e surpreendente, desestabilizador e motivador, sujeito a raios e trovões, e, claro, a momentos únicos que a sensibilidade e a sutileza podem tornar visíveis. Sendo assim, com o intuito de conquistar esses momentos que vão além da visibilidade prescrita em uma ciência moderna que delimita e dicotomiza corpo e mente, razão e emoção, sujeitos e objetos, espaços e tempos científicos, no presente estudo compartilham-se as intenções de realizar os movimentos que caracterizam os "processos necessários para o desenvolvimento das pesquisas nos/dos/com os cotidianos" (ALVES, 2003, p. 3).

No primeiro movimento, sentimento de mundo, Alves (2003) nos propõe ir além do que foi aprendido com estas "particularidades e abstrações da modernidade", que colocam a visão como sentido privilegiado, e "executar um mergulho com todos os sentidos no que desejamos estudar" (p. 3). O que a mim parece ratificar nossa intenção de manter o rigor científico sem, contudo, deixar de buscar todas as camadas de histórias que se inscrevem umas sobre as outras nas tramas tecidas nos/dos/com os cotidianos. No segundo, é necessário virar de ponta cabeça para que possamos, também, ir além de limites impostos pela prescrição com o apoio de um conjunto de "teorias, categorias, conceitos e noções" (ALVES, 2003, p. 3), que podem nos manter presos ao lugar das ciências criadas e desenvolvidas na chamada modernidade; trata-se de aprenderensinar também com as práticas e não só com as teorias. O terceiro movimento, beber em todas as fontes, traz como proposta, a utilização de fontes variadas, incluindo a produção de "praticantes" dos cotidianos (CERTEAU, 1998, p. 45) em toda sua diversidade, heterogeneidade e diferenças, bem como saberesfazeres e modos de conhecer produzidos em múltiplos contextos. O quarto, como o próprio título poetisa, é 
preciso narrar a vida e literaturizar a ciência para trazer à ciência não apenas a ficção, mas buscar na literatura, a base de uma escrita científica capaz de fazer ver/ouvir/sentir/tocar pessoas várias, o que uma escrita pretensamente neutra, imparcial e isenta não seria capaz de traduzir, e que estão por aí, vivas, soltas, livres, fragmentadas, visibilizadas por uns e invisibilizadas por outros, até porque uma pessoa não ser vista por uma determinada perspectiva não significa necessariamente não ser vista. Para finalizar, o quinto movimento, incluído posteriormente por Alves (2003), advém da percepção de que faltava trabalhar os sentimentos de mundo das pessoas praticantes desses cotidianos e não apenas de quem estava mergulhando nos cotidianos com a pesquisa. Para tanto, o movimento foi chamado Ecce Femina, "mais apropriado aos cotidianos de nossas escolas" (ALVES, 2003, p. 6), nesse caso, uma referência à frequência maciça de mulheres atuando na Educação Básica, mas que traz, em sua compreensão, o respeito ao sentimento de todas as pessoas praticantes dos cotidianos.

\section{Experiência estética e cotidianos}

A aula que aqui nos serve como dispositivo aconteceu em novembro de 2016. Na ocasião, as propostas pedagógicas envolviam a realização de uma exposição de artes com várias atividades desenvolvidas pelas crianças, ao longo de vários meses, e uma apresentação de dança e música para as outras turmas e para pessoas responsáveis pelas crianças da própria turma. As análises permitiram apontar, por exemplo, intersecções entre o aqui e agora, o tempo real e o tempo virtual com os cotidianos, que se apresentam para além de qualquer configuração pré-concebida ou planejamento que preveja uma experienciação anterior à própria experiência, que aqui é entendida como aquilo que nos toca, que nos passa, que nos atravessa, e que depende de tempo (LARROSA, 2002). A falta de tempo, relacionada com a pressa, a correria, a velocidade com que precisamos nos mover e mover o que está em nosso entorno, quando não somos movidos por ele, impede que percebamos um processo durável que possibilite a estabilização de uma memória, pois um acontecimento é imediatamente substituído por outro. Como podemos, então, nos deslocar em espaços-tempos aparentemente fixos em que por vezes pensamos nos encontrar? Que experiências nos tocam, nos movem ou comovem, cotidianamente?

Dewey (2010), em 1934, trouxe para a arte e para a educação uma nova forma de pensar experiência. Aproximando experiência estética e cotidianos, o autor dizia que "fazemos experiência o tempo todo" e que "a experiência é a base de nossa relação com o mundo, com a vida" (p. 41). Em sua concepção, a "aquisição" de conhecimento se dá pela 
experiência, a partir das necessidades e interesses das pessoas e o que a definiria seriam os episódios e situações capazes de integrar a dispersão própria dos cotidianos. Essa integração produziria "uma experiência", e essa experiência singular só poderia ser constatada após seu final, já que as experiências cotidianas se dão em passagens, movimentos, fluxos contínuos. Para ele, a experiência ultrapassaria os domínios da arte, podendo dar-se em qualquer instância da vida cotidiana, e os cotidianos escolares não seriam entendidos como lugares de preparação para a vida por serem eles mesmos a própria vida. A estética estaria, assim, presente em qualquer experiência que se desenvolve integrando o sensível e o inteligível. $\mathrm{Na}$ educação, "ainda que o pragmatismo de Dewey não nos pareça suficiente para dar conta das multiplicidades e da possível fragmentação das experiências estéticas contemporâneas", como alerta Carvalho (2014, p. 2962), a experiência seria a propulsora do aprendizado e a experiência anterior sempre usada a fim de sugerir propósitos e métodos para se produzirem experiências novas, podendo surtir os efeitos esperados ou não.

Em Gumbrecht (2010, p. 22), embora sua ideia de cotidiano esteja mais centrada "nos fluxos cognitivos habituais e nas coisas automatizadas", conforme adverte Soares (2013) em uma conversa, experiência estética e cotidianos também são aproximados e a chave para a "definição" está na "presença” e no "estranhamento" (GUMBRECHT, 2010, p. 22) ao que nos é familiar. O autor sugere, questionando a tese da universalidade da interpretação, que "concebamos a experiência estética como uma oscilação (às vezes uma interferência) entre efeitos de presença e efeitos de sentido", e afirma que a expressão "produção de presença" sublinha o efeito de tangibilidade que surge com as materialidades de comunicação e é, também, um efeito em movimento permanente (p. 38). Importante ressaltar que a "presença", ao mexer com o corpo e os sentidos, foi relegada, pela ciência moderna, em seu lugar de pensar abstrato, racional, em que o corpo se caracteriza como objeto de estudo e a mente como objeto de reflexão teórica. Isso quer dizer que muito interessa pensarmos não só como somos afetados e podemos afetar, "verbalmente", os espaçostempos "ditos" habituais, já sabidos, já vividos com todos os sentidos possíveis, mas/e, também, como a prática docente dentrofora da instituição escolar pode mobilizar afetos, "substantivamente", de forma plural e a partir de interesses e prazeres que podem ser reescritos continuamente, sobretudo com aportes críticos pensadospraticados desde os "conjuntos de imposições estimuladores da invenção, regulamentações para facilitar as improvisações” (CERTEAU, 1998, p. 50). Ao aproximar experiência estética, cotidianos e educação, buscamos em Gumbrecht (2010, p. 125) sua convicção de que "o campo da experiência estética deve ser muito mais amplo do que o conceito de experiência estética consegue abranger". Para 
pensarmos sobre a necessidade de estranhar o que nos parece familiar, Renato J. de Oliveira (2010) traz uma importante reflexão:

[...] ao estimular o debate e a problematização acerca de normas, hábitos e formas de conduta, o professor contribui para que o aluno reflita sobre o que pode ser considerado ético ou não ético e não apenas repita o que é dito por outros. Um exemplo simples diz respeito ao conhecido enunciado "fazer ao outro o que desejarias que ele fizesse para contigo" (regra de ouro). A princípio pode parecer apenas um enunciado genérico semelhante ao "ama ao próximo como a ti mesmo". Entretanto, se for problematizado, isto é, acompanhado por questões como "quais seriam os interesses do outro?" ou "de que modo o outro pode se interessar pelos nossos interesses?", abre-se a perspectiva do debate. As diferenças, então, poderão ser negociadas, as hierarquias de valores confrontadas, os juízos e as ações revistos (p. 132).

Ainda sobre experiência e cotidianos, Larrosa $(2002$, p. 19) diz que "é o que nos passa, o que nos acontece, o que nos toca. Não o que se passa, não o que acontece, ou o que toca" e complementa dizendo que "nunca se passaram tantas coisas, mas a experiência é cada vez mais rara." Para esclarecer, Larrosa faz algumas colocações. A primeira é que vivemos cercados pelo excesso de informações e que devemos separar experiência de informação, já que esta impossibilita experienciar o que nos levaria ao saber (sabedoria). A segunda é que estamos sempre prontos a opinar a partir do que nos informamos, sem um profundo e necessário (re)conhecimento de fato, ou seja, a "obsessão" e o "imperativo" de se ter uma opinião nos privam das possibilidades de experiência. E mais: opinar quase sempre nos coloca em uma posição dicotômica que apenas nos permite escolher entre ser contra e ser a favor. A terceira está relacionada ao tempo ou a "falta de". A pressa, a correria, a velocidade com que precisamos nos mover e mover o que está em nosso entorno, quando não somos movidos por ele, impedem que percebamos um tempo "durável", que possibilite a "estabilização" de uma memória, pois um "acontecimento" é imediatamente substituído por "outro". Ao sujeito do estímulo, da vivência pontual, tudo o atravessa, tudo o excita, tudo o agita, tudo o choca, mas nada lhe acontece. E a quarta está no excesso de trabalho, já que "o sujeito moderno, além de ser informado, opinar, estar permanentemente agitado e em movimento, é um ser que trabalha e que pretende conformar o mundo segundo seu saber, poder e vontade" (p. 24). Como fazer, então, se as experiências são produtoras de memórias, sejam elas alegres, emocionantes ou tristes? E se o autor diz que a velocidade e o que ela provoca, a falta de silêncio e de memória, são também inimigas mortais da experiência?

É aqui que paramos. Não para dizer o quanto parece impossível "experienciar" em meio aos fluxos contínuos cotidianos, mas para "investir" naquilo que nos parece impossível 
quando imersos nos espaçostempos que "habitamos" temporariamente. É aqui que a experiência estética de Gumbrecht (2010) toca o sujeito da experiência de Larrosa: na pausa, na interrupção, no perigo, no estranhamento. "O sujeito da experiência se define não apenas por sua atividade, mas também por sua passividade, por sua receptividade, por sua disponibilidade, por sua abertura" (LARROSA, 2002, p. 19), que se dá em meio à "experienciação" (GENDLIN, 1997, p. 240) cotidiana que transforma e possibilita um fazersaber que vai além de prescrições; um fazersaber que não pode separar-se do indivíduo concreto em quem encarna (LARROSA, 2002).

Se a experiência não é o que acontece, mas o que nos acontece, duas pessoas, ainda que enfrentem o mesmo acontecimento, não fazem a mesma experiência. $\mathrm{O}$ acontecimento é comum, mas a experiência é para cada qual sua, singular e de alguma maneira impossível de ser repetida. [...] Não está, como o conhecimento científico, fora de nós, mas somente tem sentido no modo como configura uma personalidade, um caráter, uma sensibilidade ou, em definitivo, uma forma humana singular de estar no mundo, que é por sua vez uma ética (um modo de conduzir-se) e uma estética (um estilo) (LARROSA, 2002, p. 27).

Se, em princípio, Gumbrecht (2010) nos acena com a ideia de cotidiano repetitivo, de automatização e não de lugar de lutas e enfrentamentos (CERTEAU; GIARD; MAYOL, 2013), recorremos a Gendlin (1997) para propor uma forma de pensarsentir os estranhamentos, os choques, as rupturas, como inseparáveis dos cotidianos. Para se referir ao caráter processual da experiência, o autor utiliza o conceito de "experienciação" (p. 240) (tradução de alguns autores para a língua portuguesa); um processo de sentimento vivido, corpórea e concretamente, fluxo experiencial que move e que alimenta a vida subjetiva em cada um de nós. Suspiros, lágrimas, alterações de voz, movimentos corporais, são algumas das reações que podem nos fazer perceber uma alteração na perspectiva que temos de nossas experiências e que podem se desdobrar em novas percepções ou apenas provocar uma sensação de relaxamento/tensão momentânea. "Experienciação", portanto, não significa algo acabado, mas uma potência capaz de adquirir qualquer forma e que se dá, continuamente, sempre no presente imediato, no "aqui e agora" cotidianos.

\section{Ubuntu! Sou quem sou porque somos todos nós}

(...) Lá (África) eles têm uma filosofia que chamam de Ubuntu, que é "sou quem sou porque somos todos nós”. E aí eu li, e vi o vídeo no YouTube. (...) Um homem (antropólogo) resolveu comprar muitas balas e doces e combinou com as crianças da tribo que ele, então, ia fazer uma brincadeira. Botou as balas e os doces no balaio, longe deles, e falou: - é uma corrida, quem chegar primeiro vai comer todas as balas, pode pegar todas as balas, o balaio de doces. Na hora em que ele deu a largada, todas as crianças deram as mãos e correram juntas pra pegar essas balas, 
RELACult - Revista Latino-Americana de Estudos em Cultura e Sociedade

e eu sempre me emociono quando... É por causa dessa emoção que eu contei essa história aqui (...). - Ubuntu, tio! Como uma de nós poderia ficar feliz se todas as outras iriam ficar tristes? Disse uma das crianças olhando para o antropólogo.

Essa história foi contada oralmente por Lúcia, docente de uma turma de Educação Infantil. Em uma de nossas conversas, Lúcia disse que enveredou por suas pesquisas sabendo que, desde pequena, o Outro despertava muito interesse, "queria saber como era estar no seu lugar”. Então, para chegar até aquele momento, primeiro foi buscar livros que traziam contos africanos e depois realizou pesquisas na internet sobre a cultura africana e levou as imagens para a turma.

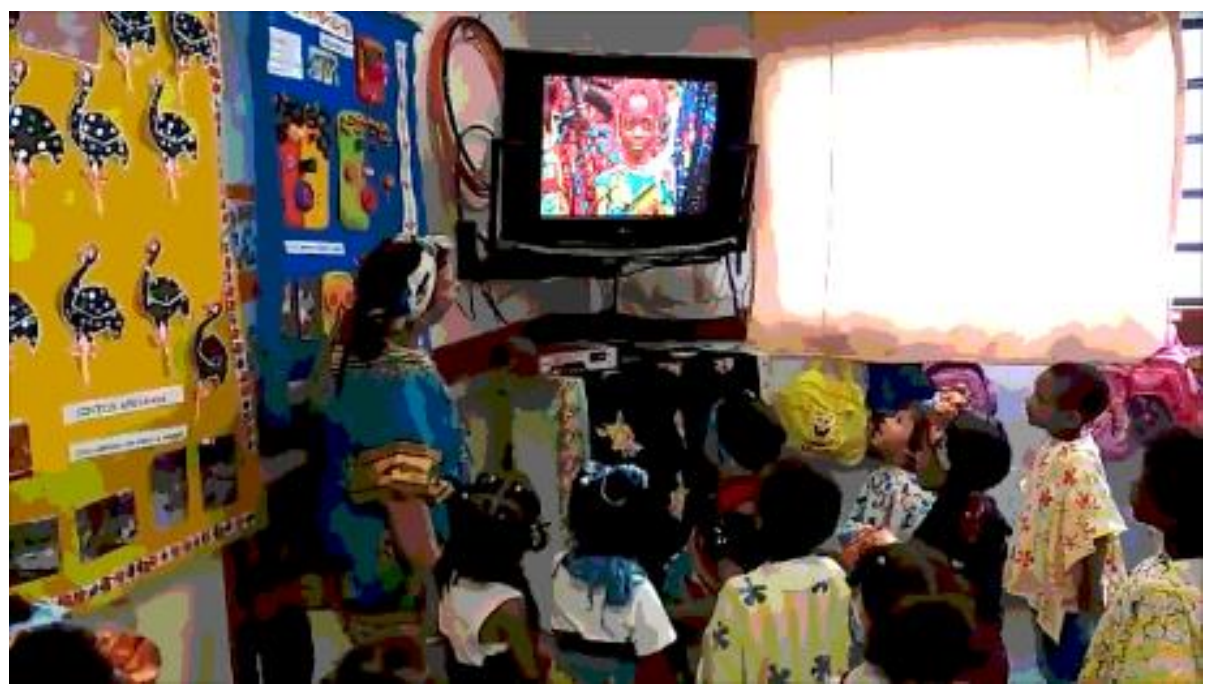

Figura 1 - Exposição na Tela da TV Fonte: Autora

Era uma tarde de primavera e o sol não esquentava com muita intensidade quando ouvi aquelas batidas fortes de atabaque que rompiam com as paredes da sala de Lúcia, ecoando pelos corredores e pelas salas da unidade escolar. Senti um arrepio. Mas, não só eu. Todas as pessoas que foram tocadas por aquele som, seja de que forma isso tenha ocorrido, voltaram sua atenção para saber do que se tratava. Era um pequeno ensaio com as crianças que não ficaria mais restrito ao espaço da sala de aula, pois aquele tambor com sonoridade grave e alta já havia nos levado para outros espaços-tempos. Lara, com sua turma, sem nenhuma combinação prévia, foi a primeira a seguir o som que aguçara sua curiosidade.

Alguns dias antes, Lúcia havia me pedido para converter, em MP3, um vídeo encontrado no YouTube. Podemos usar o amplificador e colocá-lo em funcionamento no dia da apresentação para ajudar na propagação do som, já que o ambiente fica muito ruidoso quando juntamos as crianças, os responsáveis e a equipe em lugares mais fechados, sugeri. 
Mas, não era só por isso, havia em Lúcia a intenção de não deixar que a sobreposição das imagens, virtual (exibição do vídeo com o grupo Mwamba Rock Choir) e física (crianças caracterizadas com panos africanos, cantando e dançando), produzisse efeitos de comparações antes do término da apresentação. 'Kanga', no Kênia, 'pagne', no Congo e no Senegal, ou 'capulanas', em Moçambique, por exemplo, os panos africanos produziriam, naquele momento, além da própria simbologia, efeitos de cores e amplos movimentos corporais. Ao me entregar a cópia do vídeo, Lúcia comentou sobre uma pequena preocupação com a música já que não gostaria de incitar discussões sobre questões religiosas e a mesma trazia o refrão "halellujah/ eh/ halellujah" ao som do atabaque e outros instrumentos de igual força rítmica e melódica. Concordamos que essas possíveis discussões deveriam ficar a cargo das pessoas que sentissem necessidade de se colocar, mas que não deveríamos deixar de compartilhar algo que as pesquisas trouxeram com tamanho vigor. E assim foi feito. Assisti ao vídeo e fiz a conversão, logo percebendo a potência daquela música e daquelas imagens.

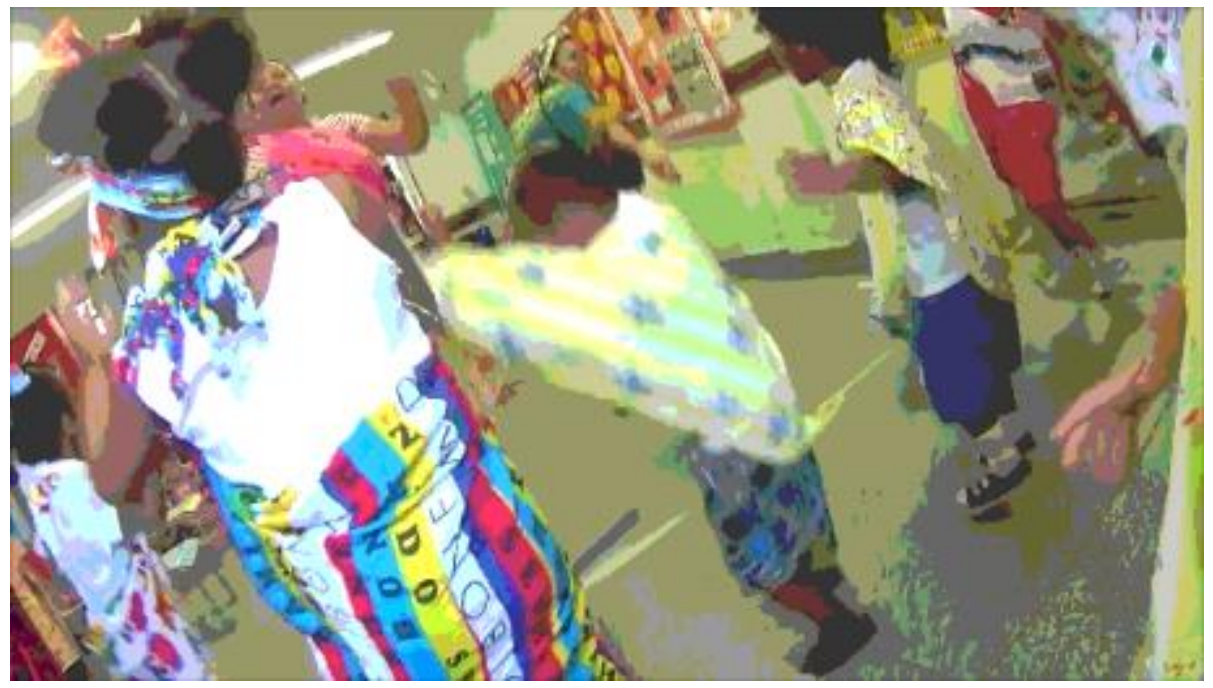

Figura 2 - Apresentação de dança Fonte: Autora

Já havia assistido a apresentação algumas vezes, depois de ajudar a colocar as crianças de outras turmas na sala e filmar cada exibição. Cada pessoa reagia de uma forma diferente aos sons, aos movimentos, às imagens que a envolvia. Se o primeiro grupo de crianças permaneceu sentado, os que vinham a seguir já não se continham e queriam dançar junto. Uma das turmas pulou, dançou e tentou cantar, exceto Malu, que olhava e permanecia quase imóvel recostada em uma cadeira próxima à porta. A mãe de Malu dizia para ela não dançar, que dança não era coisa de Deus. Em meio à euforia, entusiasmo e agitação do momento, não pudemos perceber o que havia acontecido com Malu, apenas quando revimos um dos diversos 
vídeos gravados por celulares que eram sacados quase ao mesmo tempo por quem assistia as apresentações é que foi possível observar que a pequena Malu seguia à risca o que sua mãe dizia sobre dançar.

As crianças sorriam, pulavam e continuavam tentando cantar e dançar enquanto retornavam para a sala. Demorei um pouco com algumas delas. Deixei o grupo e voltei para filmar a apresentação programada para as pessoas convidadas. Havia começado. A sala estava enchendo e o jeito era capturar as imagens sem atrapalhar a narração de Lúcia. Falando ao microfone do amplificador de voz, enquanto imagens que remetiam à África e às atividades desenvolvidas pelas crianças rodavam na tela da TV presa na parede ao fundo da sala, Lúcia narrava todo o processo de criação e produção vivido naquele período. Eu olhava pela tela do celular e observava que a maioria das pessoas também filmava com o celular (será que estariam prestando atenção? Será que ouviam o que Lúcia estava dizendo? E que ela estava emocionada?). Foi quando uma mãe chegou correndo e parou na porta, tentando uma brecha para entrar. - Acabei de ver o vídeo do meu filho dançando no Face, falou, quase gritando. Desci correndo, não podia perder. Nem sei quem postou lá. Ainda bem que eu vi. E cheguei a tempo. Ubuntu! Pensei.

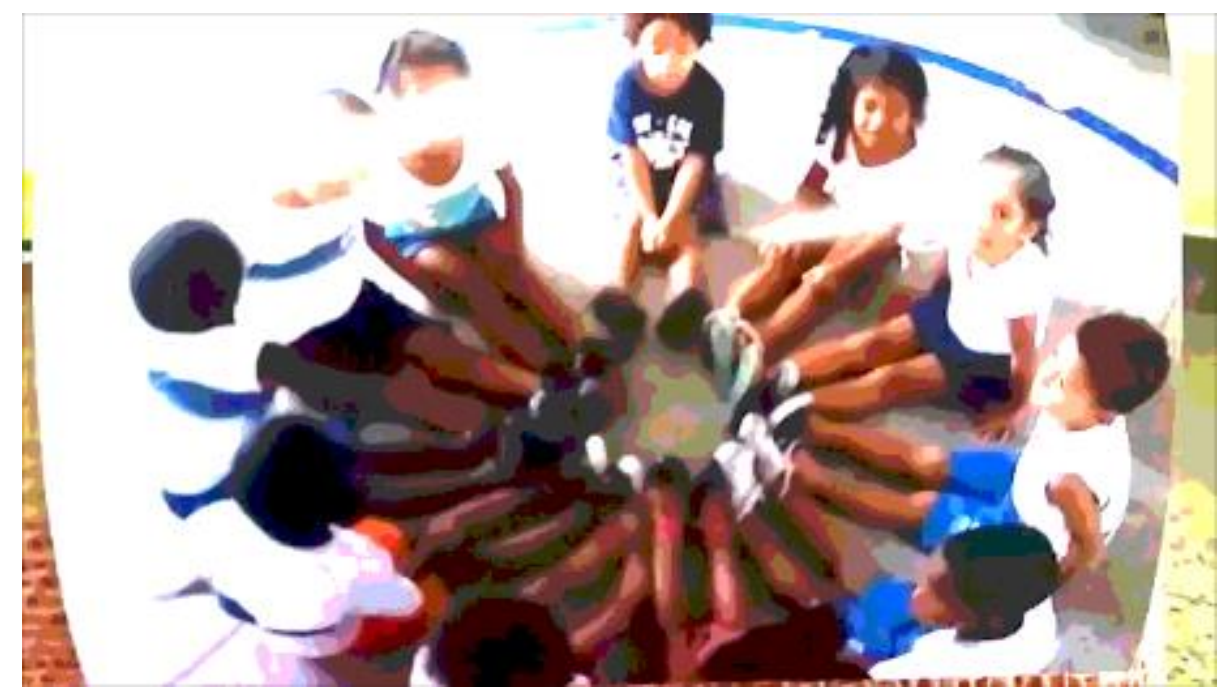

Figura 3 - Crianças sentadas Fonte: Lúcia

\section{Corpos e práticas de uma "singularidade plural"}

Cada cultura prolifera em suas margens. Produzem-se irrupções, que designamos como "criações" relativamente a estagnações. Bolhas saltando no pântano, milhares de sóis explodindo e se apagando na superfície da sociedade. No imaginário oficial, 
elas figuram como exceções ou marginalismos. Uma ideologia de proprietários isola o "autor", o "criador" ou a "obra". Na realidade, a criação é uma proliferação disseminada. Ela germina. Uma festa multiforme infiltra-se por toda parte, [...] A criação é perecível. Ela passa, pois é ato. [...] é essencialmente relativa a uma coletividade. [...] é criador o gesto que permite a um grupo inventar-se (CERTEAU, 2012, p. 242).

Certeau (2012b) chama para "ver" que os cotidianos estão "semeados de maravilhas, espuma tão fascinante, nos ritmos prolongados da língua e da história, quanto a dos escritores ou dos artistas" (p. 245). Criar é coproduzir o/no presente, tomando espaços privilegiados, utilizando instrumentos que se encontram disponíveis ou são garimpados com destreza, dedicação ou sorte. Não há divisões entre quem produz e quem cria. Há ações, transformações, movimentos. Ter criatividade é reempregar e associar materiais heterogêneos. É "fazer algo com alguma coisa" e "fazer algo com alguém".

Para falar sobre cultura e como ela é praticada nos cotidianos, Certeau, Giard e Mayol (2013) falam de três prioridades que "se impõem": a oralidade, a operatividade e o ordinário, ou os atos da vida cotidiana. Como ressaltam os autores, essas prioridades nunca deixaram de existir; apenas foram invisibilizadas e/ou deixadas de lado nos discursos gerados na academia idealizada pelo projeto de modernidade, mas, "assim como a sexualidade reprimida pela moral burguesa retornava nos sonhos de pacientes de Freud, essas funções da socialidade humana retornam sob o manto da 'cultura popular', no nosso espaço social e cultural" (p. 335-336). Quanto aos aspectos das operações, seriam divididos em três: estético, polêmico e ético. Aos aspectos prefiro chamar dimensões, relacionando-as às práticas cotidianas como fazem os autores. É na dimensão estética que "abre-se um espaço próprio numa ordem imposta, exatamente como faz o gesto poético que dobra ao seu desejo o uso da língua comum num reemprego transformante" (CERTEAU; GIARD; MAYOL, 2013, p. 336).

Apesar de ter assistido, ter convertido e saber da potência do vídeo que inspirou a apresentação da turma, não imaginava a dimensão que tomaria a sua execução. Sem que nada tivesse sido combinado antes, parte das pessoas que estavam atuando naquele horário começou a se dirigir para a sala da professora Lúcia. E, foi assim que não uma, mas cinco apresentações foram acontecendo, em sequência, à medida que uma turma saía outra entrava. Somente quem vivencia os cotidianos da Educação Infantil compreende o que significa desviar-se da "rotina" imposta por determinações de horários para refeições, sono, atividades dirigidas ou quaisquer outras atividades programadas. Embora os cotidianos, ou a chamada rotina, sejam repletos de imprevistos, cada deslocamento precisa ser apropriado e 
transformado em um novo arranjo, uma nova organização, que não pode prescindir das orientações institucionais, mas também não pode desdenhar o aqui e agora que nos move.

\section{Referências}

ALVES, Nilda Guimarães. Sobre movimentos das pesquisas nos/dos/com os cotidianos. Revista Teias: Rio de Janeiro, ano 4, n. 7-8, jan/dez. 2003.

ALVES, Nilda; BERINO, Aristóteles de Paula; SOARES, Conceição. Como e até onde é possível pensar diferente? Micropolíticas de currículos, poéticas, cotidianos e escolas. Revista Teias, Rio de Janeiro, v. 13, n. 27, p. 49-66, jan./abr. 2012.

CARVALHO, Victa de. Experiência e cotidiano na arte contemporânea. $23^{\circ}$ Encontro Nacional da ANPAP, "Ecossistemas Artísticos". Belo Horizonte, 15 a 19 de setembro de 2014, p. 2957-2970. Disponível em:

http://www.anpap.org.br/anais/2014/ANAIS/simposios/simposio08/Victa\%20de\%20Carvalho .pdf>. Acesso em: 21 maio 2018.

CERTEAU, Michel de. A invenção do cotidiano: artes de fazer. 3 ed. Petrópolis, RJ: Vozes, 1998.

CERTEAU, Michel de; GIARD, Luce; MAYOL, Pierre. A invenção do cotidiano 2: morar e cozinhar. 12 ed. Petrópolis, RJ: Vozes, 2013.

DEWEY, John. Arte como experiência. São Paulo: Martins Fontes, 2010.

FERRAÇO, Carlos Eduardo. Eu, caçador de mim. In: GARCIA, Regina Leite (Org.). Método: pesquisa com o cotidiano. Rio de Janeiro: DP\&A, 2003, p. 157-175.

GELEDÉS. Panos africanos: tradição reinventada. Postado em 13/01/2014. Disponível em: $<$ https://www.geledes.org.br/panos-africanos-tradicao-reinventada/\#gs.vC0=htY>. Acesso em: 02 Mai 2018.

GENDLIN, Eugene T. A experiência e a criação do significado: uma abordagem filosófica e psicológica da subjetividade. Illinois: Universidade do Noroeste, 1997.

GUMBRECHT, Hans Ulrich. Produção de presença: o que o sentido não consegue transmitir. Tradução de Ana Isabel Soares. Rio de Janeiro: Ed. PUC-Rio, 2010.

LARROSA, Jorge. Notas sobre a experiência e o saber de experiência. Tradução de João Wanderley Geraldi. Revista Brasileira de Educação, Rio de Janeiro, n. 19, Jan-Abr, 2002, p. 20-28.

SOARES, Maria da Conceição Silva. A Comunicação Praticada com o Cotidiano da Escola: currículos, conhecimentos e sentidos. Vitória, ES: EspaçoLivros, 2009. 